\title{
Crédito à exportação na América Latina e as regras sobre subsídios da OMC: análise de conformidade e de alternativas
}

\author{
Export Credit in Latin America and the Wto Rules \\ on Subsidies: Compliance Analysis and Alternatives
}

\begin{abstract}
José Guilherme Moreno Caiado(*)
Resumo: O presente trabalho investiga a compatibilidade do maior programa de crédito para exportação do governo brasileiro, o BNDES-EXIM, e de programas similares da Argentina e do Chile, com as regras da OMC sobre subsídios. Para tanto, descreve as condições das diferentes linhas de financiamento desses programas e as compara com as principais regras do Acordo SMC. Depois de concluir pela incompatibilidade da maior parte das linhas desses programas, o trabalho apresenta, de forma sucinta, possíveis alternativas para a atuação dos formuladores de políticas públicas nacionais, e também a opção regional representada pelo projeto de criação de um banco de desenvolvimento latino americano.
\end{abstract}

Palavras-chave: Organização Mundial do Comércio; Acordo sobre Subsídios e Medidas Compensatórias; Crédito às Exportações; BNDES, Banco do Sul.

\begin{abstract}
This paper investigates the consistency of Brazil's major export credit program, the BNDES-EXIM, as well as similar programs of Argentina and Chile, under the rules of the SCM Agreement. In order to do so, the chapter describes the main aspects of the WTO rules on subsidies, and compares them to the conditions offered by these programs. After concluding for the inconsistency of most of them, the paper briefly presents possible alternatives for policy makers to bring the national and regional legislation into conformity, and briefly debates the regional proposal of establishment of a Latin American development bank.
\end{abstract}

Keywords: Latin American Critical Tradition, Development, Underdevelopment, ECLAC, Marxist Theory of Dependency.

(*) Mestre em Integração da América Latina pelo Programa de Pós-Graduação em Integração da América Latina da Universidade de São Paulo - PROLAM/USP e Doutorando em Direito pela Faculdade de Direito da Universidade de Hamburgo, Alemanha. E-mail:<josegmcaiado@gmail.com>. Recebido em 12.3.2011 e aceito em 13.10.2011. 


\section{INTRODUÇÃo}

Em setembro de 2006, o Banco Nacional de Desenvolvimento Econômico e Social (BNDES) publicou documento em que técnicos do governo brasileiro expressavam grande preocupação com possíveis alterações no atual Acordo sobre Subsídios e Medidas Compensatórias (Acordo SMC) da Organização Mundial do Comércio (OMC). O documento considera, em linhas gerais, que a redefinição do conceito de subsídios, proposta pelos americanos, ou a expansão da lista de subsídios proibidos, defendida pelos europeus, limitaria a ação de bancos de desenvolvimento e de outras instituições públicas de financiamento no mercado de crédito (Fernandes et al., 2006, 4/7).

A intervenção do governo nesse mercado pode ser dividida, grosso modo, em três áreas diferentes: regulação, política monetária e alocação de crédito. A regulação refere-se às regras e instituições públicas voltadas para a preservação do funcionamento do mercado nacional. A política monetária, por sua vez, atua sobre a quantidade de moeda, ou a taxa de juros de curto prazo. Já a alocação de crédito tem como propósito o direcionamento de recursos financeiros para o atendimento prioritário de setores da economia, de regiões do território nacional e de categorias de companhias específicas (Torres, 2007, 277).

A alocação de crédito, por sua vez, possui um caráter determinado, oferecendo recursos públicos a pessoas ou grupos escolhidos pelo governo, que definirá o volume a ser ofertado e também as condições do financiamento como, por exemplo, a taxa de juros e o prazo para pagamento. Por meio desse expediente, o governo procura ofertar fundos a pessoas e setores que, seja pela escassez de crédito do mercado, seja pela alta taxa de juros dos financiamentos disponíveis, não teriam normalmente acesso ao crédito. Dessa maneira, a alocação de crédito é um importante instrumento de política pública, direcionando recursos a setores e pessoas tidos como prioritários pelo governo, seja por motivos econômicos, políticos ou sociais.

Um dos setores que atualmente se beneficia de programas de direcionamento de crédito na América Latina é o das empresas exportadoras, por meio de financiamentos específicos para o comércio internacional. Há três modalidades principais de direcionamento para essa finalidade: (i) financiamento direto; (ii) equalização da taxa de juros ${ }^{(1)}$; e (iii) garantia pública ao crédito $^{(2)}$.

Na modalidade financiamento direto, o setor público pode financiar tanto a produção de bens destinados à exportação, como pode, também, financiar qualquer uma das partes do contrato de exportação (o exportador ou o importador). Atualmente, há no Brasil dois grandes instrumentos permanentes do governo federal por meio do quais se financiam

(1) A modalidade equalização atua como redutora da taxa de juros. Nesse caso, a instituição pública arca com uma parcela dos juros do financiamento privado, equalizando-a com outras taxas que lhe sirvam como referência, por exemplo, as taxas oferecidas às empresas do mesmo ramo nos mercados internacionais de crédito. O Banco do Brasil é o agente responsável por esse tipo de operação por meio do PROEX Equalização.

(2) A modalidade garantia também funciona como redutora da taxa de juros, pois minimiza os riscos de inadimplência do financiamento. Por meio dela, o governo fornece garantias sobre o pagamento do crédito, assumindo riscos e reduzindo a taxa de juros. No Brasil, esse tipo de seguro é oferecido pela Seguradora Brasileira de Crédito às Exportações (SBCE), uma empresa privada com a participação acionária de grupos financeiros da França e do Brasil, dentre os quais o Banco do Brasil e o BNDES. 
mercadorias dos mais diversos setores da economia, o Programa de Financiamento às Exportações - PROEX Financiamento, de responsabilidade do Banco do Brasil, e o BNDES-EXIM, do Banco Nacional de Desenvolvimento Econômico e Social (BNDES) ${ }^{(s)}$. Diversos outros países $^{(4)}$ da América Latina também oferecem, por meio de bancos estatais, direcionamento de crédito para o financiamento de exportações, como por exemplo o argentino, por intermédio do Banco de La Nación, e o chileno, pela Corporación de Fomento de La Producción (CORFO). Esses programas de direcionamento, por envolverem transferências de recursos do governo para o setor privado, aproximam-se do conceito de subsídio ${ }^{(5)}$, cuja concessão é internacionalmente regulada pelo Acordo SMC da OMC.

Esse acordo define subsídios como uma contribuição financeira do estado para a iniciativa privada e que confira uma vantagem às empresas beneficiárias. $\mathrm{O}$ conceito de contribuição financeira é suficientemente amplo para abranger diversas formas de ações governamentais, como o financiamento por meio de bancos públicos ou mediante instruções aos bancos privados, e não será objeto de análise mais detalhada. As atenções serão voltadas à existência de concessão de vantagem, e sua eventual justificação por meio do primeiro parágrafo da letra k do Anexo I do Acordo SMC.

Entretanto, o que exatamente significa conferir uma vantagem? Como determinar se há uma vantagem na concessão de empréstimo de bancos públicos a agentes privados? Embora o artigo $1^{\circ}$ do Acordo SMC tenha ilustrado certas ações que devem ser consideradas como contribuição financeira, não ofereceu quaisquer exemplos concretos de situações em que uma vantagem seja concedida. Isso ficou a cargo da jurisprudência, que determinou que coubesse à dinâmica do mercado exercer o papel de marco referencial para essa análise ${ }^{(6)}$. Mas qual mercado deve ser usado para determinar se a vantagem foi concedida? E quais elementos devem ser confrontados com esse mercado? E de que maneira?

Ainda que condições subsidiárias de programas de financiamento possam eventualmente ser usadas para conferir vantagens ${ }^{(7)}$, nenhuma delas é tão direta como a manipulação das taxas de juros. Assim, será necessário determinar as taxas mínimas oferecidas pelos programas e compará-las às condições de mercado. Mas de qual mercado?

Para prosseguir com nossa análise, é preciso determinar qual será o benchmark usado como referência para a comparação que indicará se há ou não conferência de vantagem por

(3) O BNDES opera também outras linhas, mas estas se destinam à exportação de produtos de setores específicos, como aeronáutica ou automobilística.

(4) Este trabalho se restringirá ao Brasil e alguns países da América Latina, entretanto, o crédito à exportação é comum em dezenas de países, industrializados ou não. Para uma visão geral sobre as agências oficiais de crédito em diferentes países, que fornecem esse tipo de crédito, veja, por exemplo, OCDE 2011.

(5) O dicionário Oxford Online, por exemplo, define o termo subsídio como "uma quantidade de dinheiro concedida de fundos públicos para ajudar uma indústria ou comércio a manter o preço de bens e serviços baixo", ou para "apoiar uma indústria considerada como de interesse público".

(6) Relatório do OA em Canada-Aircraft, para 155: "Uma vantagem surge sob cada uma das orientações, se o beneficiário recebeu uma contribuição financeira em condições mais favoráveis que aquelas que lhe estavam disponíveis no mercado". Tradução livre do original: "A 'benefit' arises under each of the guidelines if the recipient has received a 'financial contribution' on terms more favorable than those available to the recipient in the market".

(7) No caso Korea - Vessels, para. 7.69, a Comunidade Europeia alegou que uma cláusula de não concorrência entre o banco estatal e os bancos privados poderia, per se, significar que os financiamentos oferecidos pelo banco estatal conferiam vantagens aos produtores de certos tipos de embarcações. 
meio dos financiamentos do BNDES. No direito da OMC, como será abaixo discutido, a referência para essa comparação são as "condições de mercado".

Mas de qual mercado? Mesmo que o limitemos a um determinado produto, como o crédito, ainda será possível verificar diferenças acentuadas dependendo do país ou da região em que o crédito foi concedido. Considerando que o investimento em títulos públicos é um dos mais seguros para o investidor, pode-se presumir que o mercado de crédito privado financiaria quaisquer outras atividades a taxas maiores que a taxa básica utilizada como referência pela política monetária. À época deste estudo, as taxas que vigoravam no Brasil, na Argentina e no Chile eram de 8,75\%, 9,73\% e 0,50\% respectivamente.

\section{Programas nacionais e sua conformidade com o Acordo SMC da OMC}

\section{Brasil}

O BNDES possui diversos instrumentos de incentivo às exportações de bens e serviços e à internacionalização de empresas brasileiras. $\mathrm{O}$ quadro atual dos incentivos à exportação, previstos no BNDES-EXIM, inclui duas modalidades principais, a $P R E^{(s)}$ e a $P O ́ S-E M B A R-$ QUE ${ }^{(9)}$, sendo que a PRÉ-EMBARQUE se subdivide em dois programas (PRÉ-EMBARQUE e PRÉ-EMBARQUE especial), duas linhas (PRÉ-EMBARQUE ágil e PRÉ-EMBARQUE empresa âncora) e, ainda, um subprograma (Programa BNDES de Sustentação do Investimento - BNDES PSI) $)^{(10)}$.

Tabela 1: Programas BNDES

\begin{tabular}{|c|c|c|c|}
\hline \multicolumn{4}{|c|}{ Brasil } \\
$\begin{array}{c}\text { Tipo de } \\
\text { financiamento }\end{array}$ & $\begin{array}{c}\text { Taxa mínima } \\
\text { atrelada ao dólar }\end{array}$ & $\begin{array}{c}\text { Taxa mínima não } \\
\text { atrelada ao dólar }\end{array}$ & $\begin{array}{c}\text { Taxa de } \\
\text { juros oficial }\end{array}$ \\
\hline PSI & $\mathrm{X}$ & $4,5 \%$ & $8,75 \%$ \\
\hline PRÉ-EMBARQUE & $1,74 \%$ & $7,15 \%$ & $8,75 \%$ \\
\hline PRÉ-EMBARQUE ÁGIL & $1,74 \%$ & $7,15 \%$ & $8,75 \%$ \\
\hline PRÉ-EMBARQUE ESPECIAL & $1,74 \%$ & $7,15 \%$ & $8,75 \%$ \\
\hline PRÉ-EMBARQUE ÂNCORA & $1,74 \%$ & $\mathrm{X}$ & $8,75 \%$ \\
\hline PÓS-EMBARQUE & $2,34 \%$ & $\mathrm{X}$ & $8,75 \%$ \\
\hline
\end{tabular}

Fonte: Dados do BNDES, organizados pelo autor.

(8) O PRÉ-EMBARQUE é uma modalidade de financiamento que oferece recursos ao ciclo de produção da empresa para uma exportação futura. É o "capital de giro que o exportador irá utilizar na compra de matéria-prima e mão de obra para a produção dos bens a serem exportados” (CATERMOL, 2005, 2).

(9) O PÓS-EMBARQUE financia exportações já realizadas e pode ser direcionado tanto ao vendedor (supplier credit) como ao comprador (buyer credit). Em uma "operação de supplier credit, a empresa vende a prazo ao importador e leva os títulos decorrentes a uma instituição financeira que os desconte e fique com os créditos vincendos da operação”. Já em uma operação buyer credit, o financiamento ocorre diretamente por um contrato de financiamento entre a agência de crédito à exportação e o importador. O financiamento PÓS-EMBARQUE permite assim que a empresa "financie seu importador e receba os recursos antecipadamente" (CATERMOL, 2005, 2).

(10) Essa designação (modalidade, programa, subprograma) segue os termos que constam nos regulamos e Cartas Circulares do BNDES que instituem os financiamentos. O trabalho usará o termo "programa" para se referir de maneira genérica às modalidades, aos programas e aos subprogramas aqui analisados. 


\section{Argentina}

O Banco de La Nación opera linhas de financiamento destinadas a promover a exportação de produtos Argentinos tais como bens agrícolas, manufaturas, serviços e bens de capital $^{(11)}$. Dessas, apenas as linhas destinadas aos bens de capital possuem prazo de pagamento superior a 18 meses, as quais serão analisadas.

A taxa de juros dessas linhas é fixa e determinada da seguinte maneira: em operações maiores que US\$100,000, a taxa é de $7 \%$ a.a.; em operações até US\$99,999, a taxa é de 8\% a.a.; e, para operações realizadas pelo Sistema de Pagamento e Crédito Recíproco da ALADI, a taxa é de $6,50 \%$ a.a..

Tabela 2: Programas Banco de La Nácion

\begin{tabular}{|c|c|c|}
\hline \multicolumn{2}{|c|}{ Argentina } \\
\hline Tipo de financiamento & Taxa de juros do financiamento & Taxa de juros oficial \\
\hline Financiamento $>100$ & $7 \%$ & $9,73 \%$ \\
\hline Financiamento $<100$ & $8 \%$ & $9,73 \%$ \\
\hline Financiamento ALADI & $6,5 \%$ & $9,73 \%$ \\
\hline
\end{tabular}

Fonte: Dados do Banco de La Nácion, organizados pelo autor.

\section{Chile}

O Chile, por meio da CORFO, oferece programas destinados ao financiamento das exportações chilenas. O objetivo do programa Crédito CORFO Exportación é "financiar até $100 \%$ das exportações chilenas" de bens de capital, entre outros bens e serviços ${ }^{(12)}$. O programa beneficia empresas chilenas exportadoras, inclusive trading companies, cujas vendas anuais não sejam superiores ou equivalentes a US\$30,000.00 ${ }^{(13)}$. O financiamento é concedido por intermédio de instituição financeira autorizada pela $\mathrm{CORFO}^{(14)}$, com prazo de financiamento de até 15 anos. A CORFO repassa os valores em moeda local ao intermediário ${ }^{(15)}$, que deve, então, efetuar o empréstimo ao exportador em dólares americanos ${ }^{(16)}$.

Há dois tipos de taxas de juros pelos quais podem optar os intermediários financeiros: a taxa fixa; e a taxa flutuante, que terá por base a LIBOR ${ }^{(17)}$. Os valores exatos são determinados pela CORFO e as taxas atualmente em vigor para os contratos de financiamento de 5, 10 e 15 anos são, respectivamente: taxa fixa: $3,45 \%$ a.a.; $3,55 \%$ a.a. e $3,70 \%$ a.a.; e taxa flutuante: LIBOR, acrescida de 2,85\% a.a.; 2,95\% a.a.; e 3,10\% a.a. Assim, considerando a LIBOR a $0,84 \%$ a.a., temos que:

(11) Para mais detalhes sobre o programa, conferir: <http://www.bna.com.ar/pymes/py_internacionales_exportadores2.asp> Acesso em: 11 mar. 2011.

(12) Item 1 do documento intitulado "Normas de Utilización del Programa de Créditos para Financiamiento de Empresas Exportadoras. CORFO EXPORTACIÓN”, segundo a redação dada pela Seção n. 05-2010, do Comité Ejecutivo de Créditos, efetuada em 2 de fevereiro de 2010

(13) Item 02, ibidem.

(14) Item 05, ibidem.

(15) Itens 06 e 07, ibidem.

(16) Item 11, ibidem.

(17) Item 08, ibidem. 
Tabela 3: Programas CORFO

\begin{tabular}{|c|c|c|c|}
\hline \multicolumn{4}{|c|}{ Chile } \\
\hline Prazo do financiamento & Taxa fixa & Taxa flutuante & Taxa de juros oficial \\
\hline 5 anos & $3,45 \%$ & $3,69 \%$ & $0,50 \%$ \\
\hline 10 anos & $3,55 \%$ & $3,79 \%$ & $0,50 \%$ \\
\hline 15 anos & $3,70 \%$ & $3,94 \%$ & $0,50 \%$ \\
\hline
\end{tabular}

Dados: Dados da CORFO e OCDE, organizados pelo autor.

Os quadros acima demonstram que dos financiamentos analisados, aqueles concedidos pelos governos do Brasil e da Argentina são inferiores às condições de mercado, o que sugere que tais financiamentos concedem uma vantagem e são, portanto, subsídios nos termos do artigo $1^{\circ}$ do Acordo SMC. A ausência de um componente relacionado ao risco do tomador nas taxas finais apenas agrava essa inconsistência, e não será objeto de uma análise mais detalhada ${ }^{(18)}$. Além disso, como as regras analisadas determinam as taxas finais, não conferindo discricionariedade ao agente de governo para negar concessões que possam conferir uma vantagem ao exportador, elas deverão ser consideradas per se inconsistentes com o Acordo $\mathrm{SMC}$, a não ser que possam ser justificadas por alguma exceção.

Por sua vez, os financiamentos concedidos pelo governo chileno por intermédio da CORFO são inferiores às condições de mercado. Isso significa que esses financiamentos não concedem uma vantagem e não são, portanto, subsídios nos termos do artigo $1^{\circ}$ do Acordo SMC. No caso dos financiamentos em até cinco anos, verificou-se que as taxas são superiores à CIRR. Isso significa que esses financiamentos não concedem vantagem nos termos do artigo $1^{\circ}$ do Acordo SMC e não são, por conseguinte, subsídios, o que afasta a incidência do Acordo SMC.

\section{A EXCEÇÃo do item (K) Do ANEXo I}

Para os programas considerados subsídios, isto é, os do BNDES e do Banco de La Nación, resta, apenas, tentar justificá-los por meio de alguma exceção. O Acordo SMC possui ao menos um porto seguro ao qual podem se apegar os subsídios vinculados à exportação, previsto na letra $k$ do anexo I do Acordo SMC (Anexo I).

a. As taxas não são inferiores àquelas a que o governo teria acesso no mercado internacional

A primeira parte da letra $k$ determina que "a concessão pelo governo... de créditos à exportação a taxas inferiores àquelas pelas quais o governo... teria [m] de pagar se tomasse [m] emprestado nos mercados financeiros internacionais recursos com a mesma maturação, nas mesmas condições creditícias e na mesma moeda do crédito à exportação..." ${ }^{(19)}$ deve ser

(18) Ao analisar os subsídios concedidos à Embraer no caso Brazil-Aircraft 21.5 (ii), o painel (para 5.35) ponderou que a CIRR é uma taxa piso, a ser cobrada de emprestadores de "primeira classe", i. e., emprestadores cujo risco de inadimplência é o mais baixo possível. Assim, um programa de financiamento à exportação que se pautasse pela CIRR deveria incluir um componente de "risco" na composição de sua taxa de juros. Uma vez que os programas do Banco de La Nación determinam uma taxa de juros fixa, sem levar o risco dos tomadores em consideração, mesmo que as taxas de juros fossem exatamente iguais à CIRR, dever-se-ia concluir que os tomadores de maior risco teriam acesso a condições melhores que aquelas que encontrariam no mercado. Confira também item C,III,3.2.1 do trabalho.

(19) Letra $k$ do Anexo I do Acordo SMC. 
considerado um subsídio à exportação. Um dos argumentos de defesa possível é: caso o governo conceda créditos a exportações a taxas não inferiores àquelas a que teria acesso no mercado internacional, não há que se falar em subsídio proibido ${ }^{(20)}$.

Nas últimas captações internacionais por meio de emissão de títulos soberanos cotados em dólares americanos, o governo brasileiro pagou taxas anuais de juros de $5,875 \%{ }^{(21)}$ nos títulos com vencimento em 10 anos, e $5,625 \%{ }^{(22)}$ naqueles com vencimento em 30 anos ${ }^{(23)}$. Já as captações cotadas em Reais brasileiros pagaram prêmios de 10,250\% para os papéis com vencimento em $21 \operatorname{anos}^{(24)}$, e 12,500\% para títulos com vencimento em $15 \operatorname{anos}^{(25)}$.

Assim, usando-se como referência as taxas dos títulos emitidos em moeda americana, temos que:

Tabela 4: Financiamento e taxas dos títulos brasileiros em dólar

\begin{tabular}{|c|c|c|}
\hline \multicolumn{2}{|c|}{ BRASIL } \\
\hline $\begin{array}{c}\text { Tipo de } \\
\text { financiamento }\end{array}$ & $\begin{array}{c}\text { Taxa mínima } \\
\text { atrelada ao dólar }\end{array}$ & $\begin{array}{c}\text { Taxa dos títulos do } \\
\text { governo brasileiro em US } \$\end{array}$ \\
\hline PSI & $\mathrm{X}$ & $5,62 \%$ \\
\hline PRÉ-EMBARQUE & $\mathbf{1 , 7 4} \%$ & $5,62 \%$ \\
\hline PRÉ-EMBARQUE ÁGIL & $\mathbf{1 , 7 4} \%$ & $5,62 \%$ \\
\hline PRÉ-EMBARQUE ESPECIAL & $\mathbf{1 , 7 4} \%$ & $5,62 \%$ \\
\hline PRÉ-EMBARQUE ÂNCORA & $\mathbf{1 , 7 4} \%$ & $5,62 \%$ \\
\hline PÓS-EMBARQUE & $2,34 \%$ & $5,62 \%$ \\
\hline
\end{tabular}

Fonte: Dados do Tesouro Nacional, organizados pelo autor.

E com os títulos em moeda brasileira, mesmo considerando os títulos com maturação de 21 anos, cujo custo de captação é menor:

Tabela 5: Financiamento e taxas dos títulos brasileiros em real

\begin{tabular}{|c|c|c|}
\hline \multicolumn{3}{|c|}{ BRASIL } \\
\hline $\begin{array}{c}\text { Tipo de } \\
\text { financiamento }\end{array}$ & $\begin{array}{c}\text { Taxa mínima } \\
\text { atrelada ao dólar }\end{array}$ & $\begin{array}{c}\text { Taxa dos títulos do } \\
\text { governo brasileiro em Real }\end{array}$ \\
\hline PSI & $\mathrm{X}$ & $10,25 \%$ \\
\hline PRÉ-EMBARQUE & $1,74 \%$ & $10,25 \%$ \\
\hline PRÉ-EMBARQUE ÁGIL & $1,74 \%$ & $10,25 \%$ \\
\hline PRÉ-EMBARQUE ESPECIAL & $1,74 \%$ & $10,25 \%$ \\
\hline PRÉ-EMBARQUE ÂNCORA & $1,74 \%$ & $10,25 \%$ \\
\hline PÓS-EMBARQUE & $2,34 \%$ & $10,25 \%$ \\
\hline
\end{tabular}

Fonte: Dados do Tesouro Nacional, organizados pelo autor.

(20) Para detalhes sobre essa argumentação a contrario e sua controversa aceitação na OMC, cf. Item C, III, 3.4 do presente trabalho.

(21) Global 2019 N (Reabertura 2), com lançamento em 15.12.2009.

(22) Global 2041, com lançamento em 30.9.2009.

(23) Página da internet do Tesouro Nacional: <http://www.tesouro.fazenda.gov.br/divida_publica/op_mercado_ internacional.asp > Acesso em: jan. 2010.

(24) Global BRL 2028 com lançamento em 19.6.2007.

(25) Global BRL 2022 com lançamento em 4.12.2006. 
Não foram encontrados dados oficiais sobre os juros pagos pelo governo argentino na emissão de títulos da dívida pública ao mercado internacional de crédito. Entretanto, informações divulgadas na imprensa argentina em 2008 estipularam em 14,8\% a taxa de juros paga pelo governo em seus títulos de menos de 10 anos. Com base nessa informação, teríamos que:

Tabela 6: Financiamento e taxas dos títulos argentinos

\begin{tabular}{|c|c|c|}
\hline \multicolumn{2}{|c|}{ ARGENTINA } \\
\hline Prazo do financiamento & Taxa de juros & Custo de captação do governo \\
\hline Financiamento $>100$ & $7 \%$ & $14,8 \%$ \\
\hline Financiamento $<100$ & $8 \%$ & $14,8 \%$ \\
\hline Financiamento ALADI & $6,5 \%$ & $14,8 \%$ \\
\hline
\end{tabular}

Fonte: Dados do Banco de La Nación e OCDE, organizados pelo autor.

Pode-se constatar que as taxas oferecidas pelo BNDES e pelo Banco de La Nación são inferiores ao custo de captação dos governos brasileiro e argentino nos mercados internacionais. Isso sugere que os financiamentos não atendem os requisitos do primeiro parágrafo da letra $k$ do Anexo I do Acordo SMC.

O segundo parágrafo excetua o financiamento do governo que constitui "pagamento" de "custos em que incorrem exportadores ou instituições financeiras quando obtêm créditos", desde que não incorram em vantagem de monta para os beneficiários.

b. O "pagamento" de "custos em que incorrem exportadores ou instituições financeiras quando obtêm créditos"

O painel em Brazil-Aircraft argumentou que, mesmo que os financiamentos concedidos por parte de uma instituição financeira a taxas de juros menores que as por ela obtidas no mercado na captação de crédito fossem abarcado pelo sentido "os custos em que incorrem instituições financeiras quando obtêm créditos", seria necessário demonstrar que essas instituições têm um alto custo de obtenção em resultado do risco Brasil( ${ }^{(26)}$. O BNDES e o Banco de La Nación possuem fontes diversificadas de recursos ${ }^{(27)}$ e, ao menos um dos mecanismos de captação do BNDES é vinculado às taxas cobradas nos mercados internacionais $^{(2 \mathrm{~s})}$. Assim, a obtenção de parcela do seu total de crédito é influenciada pelo risco Brasil. Isso significa, que o re-empréstimo desse crédito a empresas exportadoras com taxas mais baixas do que a sua captação pelo BNDES, pode sim ter o efeito de neutralizar o risco país, aproximando-se da definição acima proposta.

Ainda que a diversidade de mecanismos de captação possa enfraquecer esse argumento, o que provavelmente conduziria a uma análise da repartição contábil dos recursos do BNDES

(26) Esse cenário foi discutido pelo painel, ainda que o painel não concordasse com essa hipótese, pois considerava que o segundo parágrafo da letra $k$ não se refere aos custos do governo em obter crédito no mercado internacional, porque essa situação já está prevista no parágrafo primeiro. Cf. par. 6.73 do relatório do painel em Brazil-Aircraft, $21.5(\mathrm{i})$.

(27) PROCHNIK e MACHADO classificam as fontes de recursos do BNDES da seguinte maneira: "I. Recursos Vinculados - Fundo da Marinha Mercante e Recursos do Tesouro Nacional; II. Captações Institucionais — FAT, Depósitos Especiais, Fundo Nacional de Desenvolvimento e Organismos Internacionais; III. Ingressos Automáticos — FAT Constitucional; IV. Retorno; V. Captações em Mercado — Renda Variável, Renda Fixa e Renda Fixa — Bônus e Empréstimos no Mercado Externo; VI. Outras Entradas" (2008, 05).

(28) Captações em Mercado - Bônus e Empréstimos no Mercado Externo. 
e do Banco de La Nación para se determinar-se quais fundos deram origem ao crédito usado para o financiamento às exportações, passaremos à análise do próximo elemento do segundo parágrafo da letra $k$.

\section{c. Os pagamentos garantem vantagem de monta}

$O$ termo vantagem de monta não deve ser confundido com o termo vantagem do artigo $1^{\circ}$ do Acordo $\mathrm{SMC}^{(29)}$. Apesar da versão inglesa do Acordo SMC trazer vocábulos diferentes para o termo vantagem ${ }^{(30)}$, poderíamos explicar a relação entre vantagem e vantagem de monta dizendo que o segundo é mais restrito que o primeiro. Assim, enquanto qualquer vantagem concedida à empresa beneficiária no artigo $1^{\circ}$ é suficiente para caracterizar uma contribuição financeira específica como subsídio, nem toda vantagem bastará para que se caracterize a situação prevista na letra $k$, devendo tal vantagem ser uma vantagem de monta.

O Órgão de Apelação em Brazil-Aircraft, ao tratar de subsídios à exportação, determinou que um índice elaborado pela OCDE, a CIRR, poderia servir como base para se determinar se um determinado programa concede vantagem de monta. A CIRR é elaborada pela OCDE e estipula a taxa mínima de juros que deve ser cobrada em programas oficiais de crédito à exportação dos Membros do acordo. Em março de 2010, para financiamentos em dólares americanos, essa taxa piso variou entre $2,38 \%$ a.a. para empréstimos de menos de cinco anos a 4,07\% a.a. para empréstimos de mais de oito anos e meio. Já, por exemplo, o piso para financiamentos em Florim da Hungria é de 8,25\% ao ano.

No mercado internacional de crédito, a taxa de juros dos títulos públicos varia de acordo com a nota dos países, estabelecida por agência de notas de crédito. Segundo as principais agências, a nota ${ }^{(31)}$ do Brasil, varia entre $\mathrm{BBB}+\mathrm{e} \mathrm{BBB}-$, e a do governo argentino é "B-", segundo a Standard \& Poor's, ou seja, é mais baixo que o rating Húngaro "BBB-". Como a CIRR do Florim Húngaro é a mais alta das CIRRs disponíveis, ele será nossa referência para a comparação entre a CIRR e a taxa de juros dos financiamentos à exportação do governo argentino e dos financiamentos brasileiros concedidos em moeda local. Considerando que alguns programas oferecem taxas de juros atreladas à variação cambial do dólar

(29) Cf. o relatório do Òrgão de Apelação em Brazil — Export Financing Programme for Aircraft, para. 179. "Nós notamos que o Painel adotou uma interpretação da cláusula de vantagem de monta no item $k$ da Listra ilustrativa que é, na verdade, a mesma interpretação do termo vantagem do artigo 1.1(b) do Acordo SMC... Se a cláusula de vantagem de monta deve possuir algum sentido, ele deve ser diferente da vantagem do artigo 1.1(b)". Tradução livre de trecho do parágrafo 179 da referida decisão, cujo original se apresenta da seguinte maneira: "We note that the Panel adopted an interpretation of the "material advantage" clause in item $(\mathrm{k})$ of the Illustrative List that is, in effect, the same as the interpretation of the term "benefit" in Article 1.1(b) of the SMC Agreement adopted by the panel in Canada-Aircraft.109 If the "material advantage" clause in item $(\mathrm{k})$ is to have any meaning, it must mean something different from "benefit" in Article 1.1(b). It will be recalled that for any payment to be a "subsidy" within the meaning of Article 1.1, that payment must consist of both a "financial contribution" and a "benefit". The first paragraph of item (k) describes a type of subsidy that is deemed to be a prohibited export subsidy. Obviously, when a payment by a government constitutes a "financial contribution" and confers a "benefit", it is, a "subsidy" under Article 1.1. Thus, the phrase in item (k), "in so far as they are used to secure a material advantage", would have no meaning if it were simply to be equated with the term "benefit" in the definition of "subsidy". As a matter of treaty interpretation, this cannot be so. Therefore, we consider it an error to interpret the "material advantage" clause in item $(\mathbf{k})$ of the Illustrative List as meaning the same as the term "benefit" in Article 1.1(b) of the SMC Agreement". (omitidas as notas de rodapé)

(30) A versão em inglês do acordo, uma das autênticas, empresa vocábulos diferentes. A vantagem do artigo 1ํe designada por benefit, e vantagem de monta por material advantage.

(31) Pela Fitch, o risco soberano do Brasil é BBB-, ligeiramente inferior ao BBB da Hungria. Pela Standard \& Poor's, o índice Húngaro para crédito de longo prazo é BBB-, e o do Brasil BBB+. 
americano, usaremos como base de comparação o índice CIRR previsto para esta moeda. Assim, para os financiamentos brasileiros em real:

Tabela 7: Financiamento BNDES em real e CIRR

\begin{tabular}{|c|c|c|}
\hline \multicolumn{3}{|c|}{ BRASIL } \\
\hline $\begin{array}{c}\text { Tipo de } \\
\text { financiamento }\end{array}$ & $\begin{array}{c}\text { Taxa mínima } \\
\text { em Real }\end{array}$ & $\begin{array}{c}\text { CIRR mínima para os } \\
\text { ontratos em Florim Húngaro }\end{array}$ \\
\hline PSI & $4,5 \%$ & $8,25 \%$ \\
\hline PRÉ-EMBARQUE & $7,15 \%$ & $8,25 \%$ \\
\hline PRÉ-EMBARQUE ÁGIL & $7,15 \%$ & $8,25 \%$ \\
\hline PRÉ-EMBARQUE ESPECIAL & $7,15 \%$ & $8,25 \%$ \\
\hline PRÉ-EMBARQUE ÂNCORA & $7,15 \%$ & $8,25 \%$ \\
\hline
\end{tabular}

Fonte: Dados do BNDES e OCDE, organizados pelo autor.

Para os financiamentos brasileiros atrelados ao dólar:

Tabela 8: Financiamento BNDES em dólares e CIRR

\begin{tabular}{|c|c|c|}
\hline \multicolumn{3}{|c|}{ BRASIL } \\
\hline Tipo de financiamento & Taxa mínima atrelada ao dólar & CIRR EUA \\
\hline PSI & $\mathrm{X}$ & $2,38 \%$ \\
\hline PRÉ-EMBARQUE & $\mathbf{1 , 7 4} \%$ & $2,38 \%$ \\
\hline PRÉ-EMBARQUE ÁGIL & $\mathbf{1 , 7 4} \%$ & $2,38 \%$ \\
\hline PRÉ-EMBARQUE ESPECIAL & $1,74 \%$ & $2,38 \%$ \\
\hline PRÉ-EMBARQUE ÂNCORA & $\mathbf{1 , 7 4} \%$ & $2,38 \%$ \\
\hline PÓS-EMBARQUE & $2,34 \%$ & $2,38 \%$ \\
\hline
\end{tabular}

Fonte: Dados do BNDES e OCDE, organizados pelo autor.

Para os argentinos:

Tabela 9: Financiamento Banco de La Nácion CIRR

\begin{tabular}{|c|c|c|}
\hline \multicolumn{3}{|c|}{ ARGENTINA } \\
\hline Tipo de financiamento & Taxa de juros & CIRR Hungria \\
\hline Financiamento $>100$ & $7 \%$ & $8,25 \%$ \\
\hline Financiamento $<100$ & $8 \%$ & $8,25 \%$ \\
\hline Financiamento ALADI & $6,5 \%$ & $8,25 \%$ \\
\hline
\end{tabular}

Fonte: Dados do Banco de La Nación e OCDE, organizados pelo autor.

Dos dados acima, verifica-se que as taxas oferecidas por Brasil e Argentina estão abaixo da CIRR e que, portanto, conferem uma vantagem de monta, de acordo com a interpretação vigente da letra k do Anexo I do Acordo SMC. Isso significa que esses programas não poderiam se beneficiar dessa exceção e podem ser considerados inconsistentes.

Vale ressaltar, os financiamentos da modalidade indireta do BNDES poderiam se beneficiar mais facilmente do porto seguro da letra $k$, bastando que o Spread dos Agentes financeiros seja suficiente para elevar a taxa final de juros ao valor mínimo da CIRR. Nas simulações das taxas mínimas de juros cobradas pelo BNDES, vê-se que a diferença entre 
elas e os pisos estabelecidos pela CIRR é pequena em termos absolutos: $0,64 \%$ das taxas atreladas ao dólar, e 3,75\% dos financiamentos não vinculados ao dólar. Assim, caso o Spread do AF seja suficiente para elevar a taxa final à CIRR, sem considerar o efeito da análise de risco, todos os programas na modalidade indireta poderiam ser excetuados pela letra $k$. Entretanto, na falta de uma análise de exemplos concretos de financiamentos, isso não pode ser averiguado. Resta que, considerando-se os dados disponíveis, os programas não poderiam se beneficiar dessa exceção.

\section{A opção regional: o Banco do Sul}

Além de programas nacionais de financiamento para o incentivo às exportações, outra opção pode se viabilizar nos próximos anos na América do Sul. Em agosto de 2007, diversos países sul-americanos reuniram-se no Rio de Janeiro para discutir a criação de um banco regional. Dentre as discussões atuais, que, de acordo com Batista (2007), vão da forma de integralização do capital à incorporação de membros não latinos, definem-se os limites das funções do novo banco, ora como garantidor de liquidez em última instância, financiando déficits nas balanças de pagamento, ora com enfoque no financiamento de projetos de infraestrutura e de promoção do comércio intrarregional.

Caso o financiamento de exportações figure dentre as atividades desse novo banco, os resultados da análise dos programas nacionais de incentivo às exportações por meio do direcionamento de crédito sugerem que, para atuar em conformidade com o Acordo SMC da $\mathrm{OMC}$, as regras sobre financiamento do Banco do Sul deveriam conter previsões que vinculassem a autoridade responsável pela concessão do crédito às taxas as quais as empresas beneficiadas encontrariam no mercado privado de crédito, ou, ao menos, que ofereça discricionariedade substancial à autoridade responsável pelo financiamento para não conceder o crédito, caso haja indícios de que uma vantagem será conferida.

Mas será que uma organização internacional como o Banco do Sul teria o dever de se conduzir conforme as regras dos acordos da OMC? O GATT ${ }^{(32)}$ oferece tratamento excepcional aos processos de integração regional, dispensando-os das obrigações relacionadas à cláusula de nação mais favorecida e de tratamento nacional ${ }^{(s s)}$. Poder-se-ia argumentar, nessa linha, que caso as ações do Banco do Sul tivessem como objetivo o fortalecimento da integração regional, por meio do financiamento subsidiado de exportações entre os membros da região, suas ações estariam cobertas por esta exceção. Por outro lado, considerando que o Acordo SMC contém exceções específicas às suas obrigações, é bastante controverso se as exceções contidas no GATT também lhe seriam aplicáveis. Uma análise mais detalhada sobre a relação entre a OMC e outras organizações internacionais seria necessária para esclarecer os desdobramentos das questões aqui levantadas, mas foge do escopo do presente trabalho.

\section{Conclusões}

O trabalho desenvolveu uma análise dogmática, comparando alguns dos programas dos BNDES EXIM, do Banco de La Nación e da CORFO com Acordo SMC. Concluiu-se

(32) Acordo Geral sobre Tarifas e Comércio (sigla em inglês).

(33) Cf. artigo XXIV do GATT. 
que os programas brasileiros e argentinos são incompatíveis com as atuais regras internacionais sobre subsídios. Os programas chilenos apresentaram taxas de juros que, em razão do quadro analítico aqui desenvolvido, sugerem sua consistência, ou legalidade, com o Acordo SMC da OMC.

Considerando, então, que há uma série de compromissos políticos no GATT e no Acordo SMC que oferecem alguma margem para a intervenção do estado, analisou-se a exceção contida na letra $k$ da Lista Ilustrativa de Subsídios à Exportação do Acordo SMC e sua aplicação aos programas analisados. Essa exceção, apesar de controversa, permite que os estados concedam subsídios à exportação, desde que a taxas não inferiores às obtidas por seus governos no mercado internacional, ou, também, que não ofereçam vantagem de monta ao beneficiário do financiamento. Isso significa que os governos não poderiam conceder financiamentos com taxas de juros abaixo das taxas mínimas do mercado internacional por si obtidas, ou expressas pela CIRR.

A partir da simulação das taxas mínimas oferecidas pelo BDNES EXIM, pelo Banco de La Nación, constatou-se que todos os programas oferecem taxas abaixo das obtidas pelos governos no mercado internacional, ou abaixo da CIRR, e que, portanto, não poderiam se beneficiar da exceção contida na letra $k$. Isso nos levou a concluir que esses programas são incompatíveis com as regras do Acordo SMC da OMC.

Apesar de concluirmos que a maioria dos programas é inconsistente com o Acordo SMC, a análise demonstrou também ser possível, a partir da exceção da letra $k$, que os governos de países subdesenvolvidos ofereçam subsídios para exportação, a empresas sediadas em seus territórios, em condições de igualdade com as taxas normalmente obtidas por empresas localizadas em países desenvolvidos. Uma vez que a interpretação feita pelo OA da letra $k$ excetuaria os subsídios fornecidos a taxas de juros iguais ou maiores que a $\operatorname{CIRR}^{(34)}$. Com isso, empresas nacionais poderiam obter crédito em condições similares às obtidas por seus concorrentes de países desenvolvidos.

Isso nos leva a concluir que, no que concerne à regulação de subsídios industriais, mesmo com o maior controle sobre os países em desenvolvimento a partir da assinatura do Acordo SMC, há espaço para a elaboração de políticas de incentivo às exportações. Esse espaço seria, todavia, limitado pelo piso mínimo da CIRR, e impediria que países em desenvolvimento elaborassem uma política de proteção à indústria nacional por meio da substituição de importações ou promoção das exportações. A manutenção e a conquista de mercados ficam, assim, limitadas à capacidade da indústria doméstica de produzir bens com uma eficiência igual ou melhor que suas concorrentes internacionais.

Essa conclusão pode levantar questões sobre a justiça dessas regras, já que a maioria dos países subdesenvolvidos conta com uma base industrial escassa, cuja diversificação e consolidação dependem, em certa medida, da proteção do Estado. Por outro lado, as regras contidas no Acordo SMC não se aplicam somente aos países em desenvolvimento, e também lhes oferece proteção contra os subsídios de estados que, por disporem de orçamentos mais elevados, estariam em melhores condições de promover suas exportações.

(34) Ainda que o Painel em Brazil-Aircraft 21.5 (ii) tenha rejeitado essa interpretação, o relatório do OA em Brazil-Aircraft parece deixar aberta essa possibilidade. 
Com base nessa análise, por fim, é possível indicar alguns possíveis espaços para ação dos países em desenvolvimento que tenham aderido ao Acordo SMC. Na esfera doméstica, os governos podem instituir e manter programas de subsídios que respeitem as regras do Acordo SMC. Isso significa que os financiamentos devem conter previsões que: (i) vinculem a autoridade responsável pela concessão do crédito às taxas vigentes no mercado de crédito; que (ii) incorporem elementos de análise de risco no cálculo das taxas de juros; e que (iii) ofereçam discricionariedade substancial à autoridade responsável pelo financiamento para não conceder o crédito, caso tenha indícios de que uma vantagem será conferida. Na esfera internacional, os estados podem negociar alterações no Acordo SMC ou interpretações que relativizem o tratamento indiferenciado entre países desenvolvidos e subdesenvolvidos. Os governos podem ainda valer-se de exceções do texto do GATT, como a constituição de acordos regionais.

A alternativa regional ganha destaque ao analisar-se a possibilidade de constituição de um banco regional que poderia financiar exportações dos países-membros. Entretanto, se por um lado o GATT prevê tratamento excepcional aos processos de integração regional ${ }^{(55)}$, por outro, a aplicação das exceções contidas no GATT às obrigações do Acordo SMC é bastante controversa. Nesse sentido, uma análise mais detalhada sobre a relação entre a OMC e organizações regionais seria necessária para esclarecer os desdobramentos das questões aqui levantadas.

\section{REFERÊNCIAS BIBLIOGRÁFICAS}

BATISTA JR., Paulo Nogueira. Banco do Sul? Folha de S. Paulo, São Paulo, 19 maio 2007.

BARTON, John H. et al. The evolution of the trade regime: politics, law and economics of the GATT and the WTO. Princeton: Princeton University Press, 2008.

FERNANDEZ, Cassiana et al. Doha: países ricos querem coibir bancos de desenvolvimento. BNDES - Visão do Desenvolvimento, n.13, 21 set. 2006.

IRWIN, Douglas A.; MAVROIDIS, Petros C.; SYKES, Alan O. The genesis of the GATT. Cambridge: Cambridge University Press, 2008.

LUENGO, Gustavo. Regulation of subsidies and state aids in WTO and EC law. Alphen aan den Rijn: KLUWER, 2006.

OCDE. Export Credit Financing Systems in OECD Member Countries and Non-Member. OECD Publishing, 2007.

PROCHNIK, Marta; MACHADO, Vivian. Fontes de recursos do BNDES 1995/2007. Revista do $B N D E S$, Rio de Janeiro, V. 14, n. 29, jun. 2008.

THORSTENSEN, Vera. OMC: Organização Mundial do Comércio, as regras do comércio internacional e a rodada do milênio. São Paulo: Aduaneiras, 1999.

TORRES FILHO. Ernano Teixeira. Mecanismos de direcionamento do crédito, bancos de desenvolvimento e a experiência recente do BNDES. In: FERREIRA, Francisco M. R.; MEIRELLES, Beatriz B. (Orgs.). Ensaios sobre economia financeira. Rio de Janeiro: BNDES, 2009.

(35) Cf. artigo XXIV do GATT. 